\title{
Unconditional Basic Income's Prospects in China
}

\author{
Yuexin Pang ${ }^{1,}$, , Chi Zhang ${ }^{2, b}$ \\ ${ }^{1}$ School of Yuexin Pang, Hebei University of Economics and Business, Shijiazhuang 050051, \\ China; \\ ${ }^{2}$ School of Chi Zhang, Hebei University of Economics and Business, Shijiazhuang 050051, China. \\ aaprillily@yeah.net, b749892490@qq.com
}

\begin{abstract}
The rapid development of robots and Artificial Intelligence poses a challenge to the employment of low-level workers and even all human beings, which makes the policy of basic income necessary. China, as the most populous country in the world, should be more cautious in confronting this shock. This paper discusses the applicability of UBI in China. Using the experiments in developing countries as illustration, the paper discusses the trade-offs that need to be recognized in adopting a UBI in such contexts. The conclusion is that replacing the existing social security systems in China with a UBI will yield a positive effect on economic and social stability in the near future. For nowadays, limited by the existing economic system and per capita GDP, targeted poverty alleviation measures may be more effective. However, the replacement of man by machine is inevitable, Thus Chinese government should take precautions like conducting relevant trials.
\end{abstract}

Keywords: Basic income; Social security; welfare states; employment.

\section{Introduction}

In the 20th century, the welfare states were successful in reducing poverty, building trust between different socio-economic groups and providing more equal opportunities for all. Today, welfare state structures reflect the societies of the past rather than those of the future. Recent years have seen an exponential increase in media and policy attention around the basic income idea, followed by concrete initiatives to study basic income design and implementation across the world.

Unconditional Basic Income (UBI) is a type of program in which citizens of a country may receive a regular sum of money from government. It means a modest amount of money paid unconditionally to individuals on a regular basis. Several key characters can be extended from this definition.

\subsection{Basic}

The supply of funds is determined by policy makers in combination with fiscal revenue and budget. full basic income should be enough to meet individual's basic needs (above the poverty line), while if it is less than that amount, it is called partial basic income. Therefore, the implementation of the UBI policy does not mean the abolition of all other social welfare policies, such as disability or special disease subsidies.

\subsection{Universal}

There is a view that this general should be directed at all citizens, and in contrast, there is also a view that the basic income is only for the entire population. This issue involves the principle of benefit that resources should be considered. Most scholars believe that UBI should target citizens and residents who have lived for a certain period of time.

\subsection{Individual}

In fact, this is a very important point, because many existing welfare policies are based on family or household, which leads to a series of problems, such as contradictions within the family, inequality between men and women, and the truth that money is hard to send to the people who really need it. UBI can evade the above problems for individuals, and avoid the individual's basic rights from affecting of family, marriage, spouse and other circumstances. 


\subsection{Unconditionally}

This means that there is no income condition, no application is required, and there is no restriction on the use of funds. The existing welfare policy requires a variety of means-test, which consumes a lot of manpower and resources. Furthermore, many people who need help are unwilling to accept this review because they don't want to be classified and tagged, and thus welfare policy does not achieve its purpose. But UBI is not a simple system of freely paying money. It is a regular and stable way.

Although basic income sounds like exclusive to developed countries, it is a luxury that can only be afforded to a certain degree of affluence. However, in places that seem unaffordable, its prospects may be broader. In recent years, the National Basic Income Pilot Project has been launched in Namibia, India, Kenya and Uganda, mainly funded by NGOs. In addition to receiving wages, government funds provide more ways to make a living: anthropologist James Ferguson points out that basic Income may be a way for large demographic countries to achieve social welfare, because in these countries it is only an illusion to create jobs by population size to meet the needs of all.

At present, China is vigorously carrying out fiscal and tax reforms. The government is committed to narrowing the income gap and eliminating extreme poverty as much as possible. People are not familiar with the concept of basic income. Is there any prospect for basic income in China?

\section{Rationality of UBI}

Many people accuse UBI of being a totally unrealistic utopia. Is it really? The following is an explanation of the rationality of UBI from economic theory.

\subsection{Reasons for Implementing Welfare Policy}

Welfare Policy and Justice In the field of social policy and income redistribution, there are two mainstream ideas, utilitarianism and liberalism. Among them, the utilitarian social welfare function is that the purpose of social policy is to maximize the overall benefits, even at the expense of individual interests when necessary. The utilitarian social welfare function is the sum of personal utility, so even if the income of some members of society declines, the total social welfare can be improved, as shown in the following figure.

$$
W(x)=\sum_{i=1}^{H} u_{i}(x)
$$

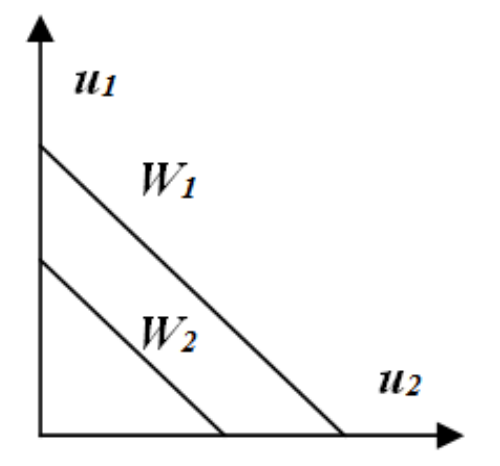

Fig 1. Utilitarian social welfare function

Liberalism prefers 'freedom', and believes that the purpose of social policy is to ensure the maximization of individual interests. The smaller the government's functions, the better. Liberals believe that the rich tax triggered by the social welfare system will dampen the enthusiasm of investors and creators. For this, the necessity of the welfare system is reflected in: first, humanitarianism, followed by the balance of power, that is, the rich spend a certain amount of money to 'buy' the poor, otherwise they will not engage in low-end labor to serve the rich, and Create social 
unrest. These theories all show that the implementation of welfare policies and income redistribution makes sense.

\subsection{Reasons for Implementing Basic Income}

Thomas Paine's "social dividend" theory. Paine believes that much of our income and wealth today stems from the efforts and achievements of our ancestors, not just our own struggles, so everyone should enjoy a certain degree of social dividends left by our common ancestors.

That is to say, UBI's most fundamental legitimacy is the social dividend that we should have in every life. This is the basic right born to the descendants of our common ancestors. Here, UBI and other welfare policies, or private philanthropy, are fundamentally different. The essence of welfare policy and private philanthropy is based on the sympathy of the strong and helping the weak. In any case, the people are divided into 'people who need help. 'And 'people who don't need help', but UBI is fair to them.

A basic income is generally advocated to help reduce income inequality, as UBI proposals are typically financed through a progressive income tax or by cutting subsidies favoring the non-poor. Figure 1 below (Ravallion, 2016) presents the case of a basic income transfer $b$ given to everyone, financed by a proportional tax at the rate $t$ on all incomes.

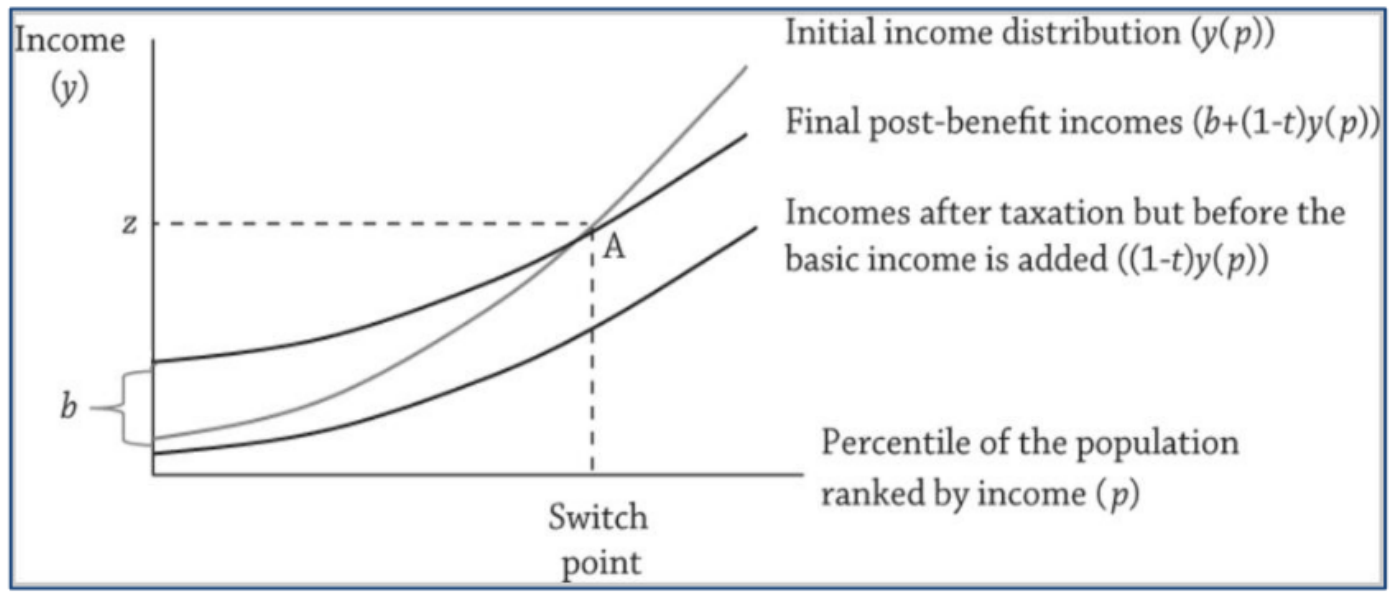

Fig 2. A basic income financed by a proportional income tax

Source: Ravalli on (2016).

\section{UBI in the Real World}

In the last part, I provide an overview of the pros and cons of UBI and their theoretical justifications. Policies must consider practicality. The following passage reviews past, existing and expected future UBI practices around the world and attempts to summarise the lessons learnt from them.

\subsection{Help Low-income Groups}

In China, despite the improvement of the college entrance examination system and the civil service examination system, it is still difficult for poor people to become elites. In the countryside, there is no money, no medical care, no education, and the peasants are trapped in poverty, from generation to generation.

Some people may ask, isn't there a targeted welfare system targeted poverty alleviation strategy'? However, there are many problems in the existing welfare system in the world. First, bureaucracy and complex paperwork have discouraged many people in need. Second, many people are reluctant to accept poverty subsidies, because receiving subsidies means that they become 'accepted poverty subsidies', especially young students, who are in the most self-respecting age. Third, those who have received subsidies and have not given up their lives face high costs in the process of finding a job. The current welfare system in Western Europe stipulates that the payment of subsidies will be stopped with a certain income, but the income of the lower-level jobs that the people receiving the subsidy 
can find is not much more than the subsidy. All in all, it is difficult for low-income groups to be trapped in poverty traps by current welfare policies.

Many people accuse UBI of being a totally unrealistic utopia. Is it really? The following is an explanation of the rationality of UBI from economic theory.

What's worse, poverty often causes uneasiness. Because of poverty, life has no predictability and security, and the poor tend not to be responsible for their future. The simplest manifestation is not to learn, to develop professional skills, and not to consider pensions. What's more, it became a potential criminal. The Didi "hitch" ride murder case, which caused a great uproar in China not long ago, is an example. The suspects in both cases were trapped by poverty, and their actions cost society a high price.

The trap of poverty is only a limitation of external conditions. The uneasiness of the trap completely cuts off the possibility of people changing their destiny. UBI can just change these disadvantages. Firstly, UBI saves cumbersome bureaucracy and a lot of paperwork. It only needs to set a suitable amount according to inflation forecasts every year and distribute it to all citizens and long-term residents. Secondly, because everyone receives the same amount of money, no one will be discriminated against in connection with the money. Third, UBI is unconditional, so it will not affect the choice of low-income people. Fourth, UBI is regular, and it is a huge guarantee both economically and psychologically. People can look to the future without worrying too much about the hardships in front of them. Some people often accuse the poor of being blind, but they have not thought that people are not short-sighted and poor. But because poverty can only be passed. UBI trials in India, Namibia and other places have proved that UBI people began to look to the future and began to pay attention to education. The trials in Namibia were even more unexpected. Without any prior planning or organization, the local residents spontaneously set up the Basic Income Advisory Committee, led by local teachers and nurses, and suggested how residents would rationally spend UBI.

\subsection{UBI's Value to the Whole Society's Economy}

UBI seems to have spent a lot of money, but the money is not spent. From the perspective of economic development, on the one hand, UBI can promote demand and increase purchasing power.

Some people think that UBI may lead to inflation. This view misunderstands that the basic income for each citizen is to increase the amount of currency issuance. In fact, UBI is the redistribution of existing funds. The allocation of funds to the poor, which contributes to the increase in per capita purchasing power and the increase in demand, can increase supply, and the increase in supply requires labor, thus reducing the unemployment rate. On the other hand, during the economic downturn, UBI can guarantee a certain degree of purchasing power, so that the economy will not collapse.

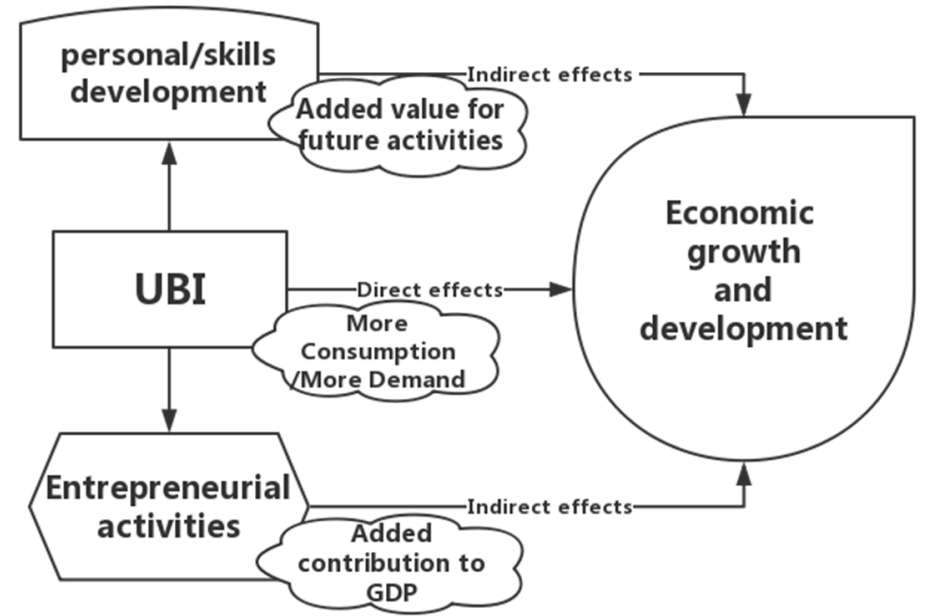

Fig 3. Effects of UBI on economic growth and development

Source: Diagram designed by author. 
At the financial level, experiments in India have shown that UBI can lower lending rates and increase the liquidity of money. Before the implementation of UBI, funds were scarce and materials were scarce. Many people needed to borrow money and few people were willing to lend money, and interest rates were pushed up. After the implementation of UBI, some of them first paid their debts and started normal life. Even if they were still unclear, the stability and liquidity brought by UBI made them have the confidence to invest rationally and choose debts with lower interest rates. Not only that, but UBI can also promote investment and the growth of SMEs.

At the investment level, UBI enables more people to have the confidence and capital to invest and take risks, and the loss will be lost. Anyway, life is guaranteed. At the supply and demand level, more people have higher purchasing power, which means that the market needs more choices, which gives small businesses and local enterprises the opportunity to develop. From the perspective of social progress, the so-called economic foundation determines the superstructure, and the above-mentioned various developments and investments can promote innovation and prosperity in all aspects of society.

Table 1. Gains and Losses from Substituting a UBI for Traditional Subsidies a) Share of Losing/Gaining Households

b) Average Losses and Gains
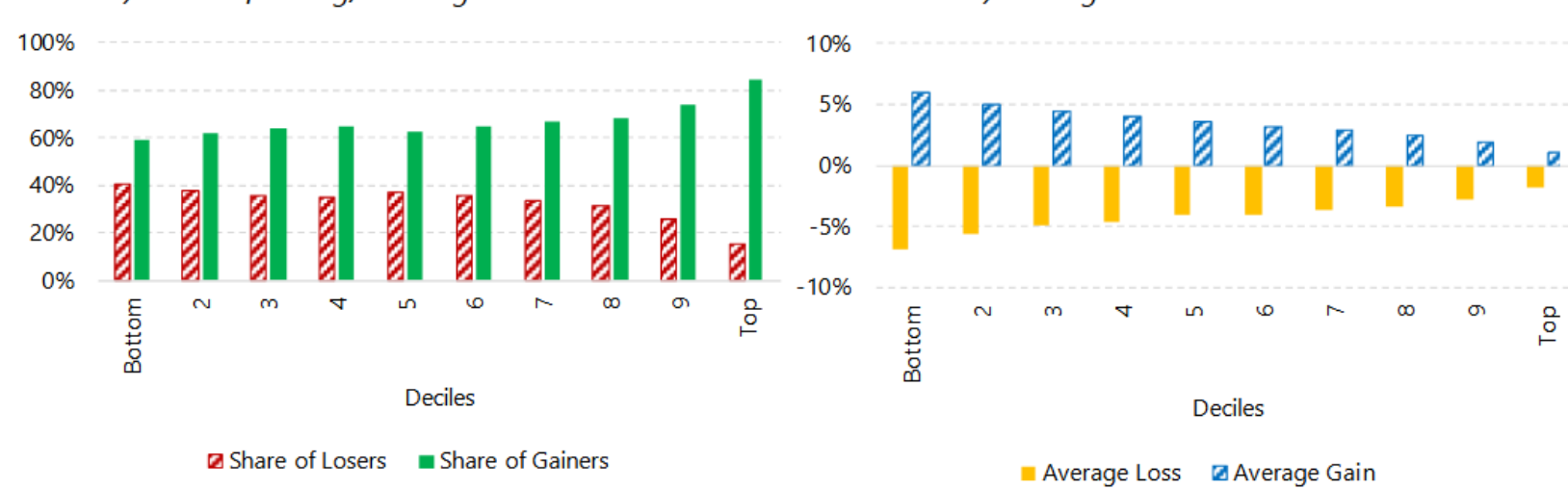

Source: David Coady 'estimates based on Indian 2011-12 NSS.

\subsection{Other Positive Results of the Indian Experiment}

In addition to the benefits of economic development, UBI itself benefits from multi-faceted social progress.

One is the affirmative movement. Since UBI is given to each individual, there is no family conditional marriage restriction, which gives each individual the freedom to choose. As a legitimate citizen, I have my own basic income and can legally live the life I want without the fear of survival and other constraints. For example, I have to admit that the male rights in the current era are still prevalent, and there are still many women who have to rely on their husbands despite their unwillingness, and UBI can give them the material basis and courage to leave the unfortunate marriage. Still in the experiment in Madhya Pradesh, in one of the villages, the photos of the young girls registered with the veil were in the beginning of the experiment, but a few months later the researchers returned and found no young woman with a veil. When a girl was asked, she said that what the elders said before they had to do something, now they have their own money, and they can decide what to do.

The second is identity, citizenship and social stability. Accepting the common heritage of this society makes people more agree that they are part of society. Therefore, the stability and development of society has become the common goal of everyone. At the same time, because of this stable income, people have more time and energy to practice their citizenship.

The third is ecological development. UBI allows people to have more choices to do creative work than to do mining resources as before. Tracing back to the source, resource exploitation and environmental pollution are exploiting society and benefiting a few rich people, so UBI can be seen 
as compensation for society. It is necessary to increase taxes on industries that pollute the environment and fossil energy.

In conclusion, UBI do has considerable opportunity in developing countries. As for China, the complications faced by the minimum living security have raised the need to look at alternative welfare policies. UBI could be a worthwhile candidate, as it may help to tackle many difficulties associated with the minimum living security program, with targeting inefficiency being one of the biggest barriers to prevent satisfactory outcomes.

\subsection{Potential Challenges to the UBI in China}

Despite the positive outlook, UBI is confronted with several potential challenges. These pertain to characteristics of imbalanced development in China and concerns about governance capacity at relevant levels, all of which have bearings on how a UBI could be enacted.

For example, heterogeneity in levels of regional development and the divide between rural and urban areas make it a formidable task to establish a uniform income threshold for UBI (Furui, 2017b).

Another problem is that, setting up a UBI in China requires a large amount of financial support. In 2014, paying every adult a monthly income of 336 yuan (if living in urban areas) or 231 yuan (if living in rural areas) would have required a yearly government expenditure of 3.472 trillion-yuan, equivalent to approximately $5.46 \%$ of overall Chinese GDP and almost half of the overall Chinese government expenditure. Furthermore, these figures could see a potential increase over the years given the pressure of inflation and of a constant rise in living standards.

\section{Conclusion}

Global advances in AI, coupled with shifts in globalization and work organization, have altered the structure of work. A new wave of technological change has resulted in increased concerns about future job losses. The question of how to maintain effective security for everyone is inextricably linked to these global trends, especially for those whose jobs would be most negatively impacted by advances in automation. The UBI is deemed as a possible solution to this growing problem. Many developed countries, represented by the Nordic welfare state, have begun to formulate reform plans. Some developing countries also have conducted small experiments.

But if the UBI is to be rolled-out on a large scale in China, a set of challenges needs to be explored sufficiently and feasible solutions need to be provided. This complicated socio-economic context will constrain the extent to which the UBI is 'universal' if it is not to be detached from such policies that implicitly preclude equality. Maybe we can start with some small trials.

The 13thFYP has devised the 'targeted poverty alleviation strategy', outlining approaches, which are widely applied to help eliminate poverty. Until now, this strategy has made great progress. It might still be an effective solution, In the near future, taking China's national conditions into consideration. But when we have to face the Unemployment disaster, is there still time for reform?

\section{References}

[1]. Furui, C. (2017a). China: A New Paradigm in the Current Basic Income Debate. Retrieved from BIEN: Basic Income Earth Network: http://basic income. Org/ news/ 2017/ 04/ china- newparadigm- current- basic- income- debate/.

[2]. Murray, M. C., \& Pateman, C. (2012). Basic Income Worldwide: Horizons of Reform. London: Palgrave Macmillan.

[3]. Neuvonen, A. (2016). Thousands to receive basic income in Finland: a trial that could lead to the greatest societal transformation of our time. Demos Helsinki.

[4]. GAO, Q. (2017). Welfare, Work and Poverty: Social Assistance in China. New York: Oxford University Press. 
[5]. Sputnik International. (2017). India Set to Approve Universal Basic Income. Sputnik International: Business. 